\title{
Royalties para cultivares, legislação e regulação: Uma meta-análise
}

\author{
Royalty fees for cultivars, legislation and regulation: A meta-analysis \\ Regalías para las cultivares, legislación y regulación: Un metaanálisis
}

Recebido: 24/03/2021 | Revisado: 30/03/2021 | Aceito: 01/04/2021 | Publicado: 12/04/2021

\author{
Eduardo José de Souza Silva \\ ORCID: https://orcid.org/0000-0003-3429-6236 \\ Universidade Federal de Sergipe, Brasil \\ E-mail: eduardojcufs@gmail.br \\ Renata Silva-Mann \\ ORCID: https://orcid.org/0000-0001-5993-3161 \\ Universidade Federal de Sergipe, Brasil \\ E-mail: renatamann@academico.ufs.br \\ Crislaine Costa Calazans \\ ORCID: https://orcid.org/0000-0002-6100-0608 \\ Universidade Federal de Sergipe, Brasil \\ E-mail: cris.calazans@yahoo.com.br
}

\begin{abstract}
Resumo
O estabelecimento de padrões e princípios para aplicação de normas de proteção de direitos de propriedade intelectual sobre as cultivares é uma medida fundamental a qualquer país, essencialmente ao Brasil, um dos países mais ricos em biodiversidade do mundo. Dessa forma, é objetivo desse trabalho realizar uma revisão sistemática para analisar a produção científica em proteção das principais cultivares protegidas, identificar parâmetros e métodos existentes para definição das taxas de royalties e os mecanismos de cobrança adotados. Foi realizada uma revisão sistemática a partir de artigos publicados no período de 10 anos, de 2009 até 2019, nas bases científicas Scopus e Web of Science. Os termos e operadores booleanos: "(royalty) and (plant variety or cultivars)" foram prospectados em título ou resumo de artigos científicos. Foram prospectados 83 documentos indexados nas bases Scopus (37) e Web of Science (46). Após o tratamento dos dados e remoção de documentos duplicados restaram 43 artigos científicos. Com uma publicação média de 6,7 publicações por ano. Média de 10 citações por documento. Um total 171 autores e 271 co-autores foram elencados, sendo cinco documentos de autoria única e em média de 3,1 autores por artigo. Após o processo de refinamento, obteve-se uma amostra de estudo de 17 artigos. Os periódicos analisados não forneceram informações de como são taxados os royalties, apenas relataram o tipo de proteção e as cultivares estudadas.
\end{abstract}

Palavras-chave: Revisão sistemática; Propriedade intelectual; Proteção de cultivares.

\begin{abstract}
The establishment of adequate standards and principles for the application of norms for the protection of intellectual property rights over cultivars is a fundamental measure for any country, essentially Brazil, one of the richest countries in biodiversity in the world. Thus, the objective of this work was to carry out a systematic review to analyze the scientific production of protection of the main cultivars, to identify existing parameters and methods for the definition of royalty rates and the collection mechanisms adopted. A systematic review was carried out based on articles published in the period of 10 years, from 2009 to 2019, in the scientific bases Scopus and Web of Science. The Boolean terms and operators: "(royalty) and (plant variety or cultivars)" were explored in the title or summary of scientific articles. 83 documents indexed in the Scopus (37) and Web of Science (46) databases were searched. After processing the data and removing duplicate documents, 43 scientific articles remained. With an average publication of 6.7 publications per year. Average of 10 citations per document. A total of 171 authors and 271 co-authors, with five documents having single authorship and an average of 3.1 authors per article. Thus, a study sample of 17 articles was obtained. the journals analyzed did not provide information on how royalties are taxed, they only reported the type of protection and the cultivars studied.
\end{abstract}

Keywords: Systematic review; Intellectual property; Protection of cultivars.

\section{Resumen}

El establecimiento de estándares y principios adecuados para la aplicación de normas de protección de derechos de propiedad intelectual sobre cultivares es una medida fundamental para cualquier país, fundamentalmente Brasil, uno de los países más ricos en biodiversidad del mundo. Así, el objetivo de este trabajo fue realizar una revisión sistemática para analizar la producción científica de protección de los principales cultivares, para identificar los parámetros y métodos existentes para la definición de tasas de regalías y los mecanismos de recaudación adoptados. Se realizó una revisión sistemática a partir de artículos publicados en el período de 10 años, de 2009 a 2019, en las bases científicas Scopus y Web of Science. Los términos y operadores booleanos: "(royalty) and (plant variety or 
cultivars)" se analizaron en el título o resumen de los artículos científicos. Se realizaron búsquedas en 83 documentos indexados en las bases Scopus (37) y Web of Science (46). Después de procesar los datos y eliminar documentos duplicados, quedaron 43 artículos científicos. Con una publicación media de 6,7 publicaciones al año. Promedio de 10 citas por documento. Un total de 171 autores y 271 coautores, con cinco documentos de una sola autoría y una media de 3,1 autores por artículo. Así, se obtuvo una muestra de estudio de 17 artículos. las revistas analizadas no proporcionaron información sobre cómo se gravan las regalías, solo informaron el tipo de protección y los cultivares estudiados.

Palabras clave: Revisión sistemática; Propiedad intelectual; Protección de cultivares.

\section{Introdução}

Os seres humanos praticam a seleção de plantas, sendo primeiramente realizada de forma empírica e após o século 20 , com base em princípios baseados na genética de forma científica. Com o aumento populacional, e consequentemente, maior demanda por alimentos o estabelecimento de novas variedades de plantas torna-se uma ferramenta importante para o estabelecimento de cultivos mais produtivos.

Os termos variedade e cultivar são usados na área agronômica ou florestal ou ambiental, nas quais os indivíduos de uma espécie apresentam variação natural e podem ser usados em nível comercial, após cruzamentos e ciclos de seleção. O termo variedade é utilizado quando alguns indivíduos de uma dada espécie diferem dos demais no que se refere à caracteres botânicos, produtivos e fisiológicos. Portanto, as variedades geralmente são variações naturais ou intencionalmente obtidas por melhoristas para se atender aos ganhos produtivos, resistência a pragas e doenças, ou características botânicas que facilitem a produção.

Por outro lado, o termo cultivar, que deriva do termo "variedade cultivada" (cultivated variety em inglês), é usado quando a planta se distingue das demais por meio descritores homogêneos e estáveis (DHE) e tem potencial para uso no setor agroindustrial. Assim, a planta é cultivada por apresentar características que levem a ganhos produtivos. O termo cultivar é atribuído ao resultado do melhoramento em uma variedade de planta que a torne diferente das demais em seus descritores, como por exemplo, sua coloração, porte e resistência a doenças, de modo que a nova característica seja igual em todas as plantas da mesma cultivar, ao longo das gerações (FAO, 2021), obtidas com a multiplicação do material propagativo usado na obtenção de plantas em campo.

No melhoramento de plantas tem-se o uso de cultivares em um processo de melhoria de safra que atende continuamente às necessidades de mudança no setor produtivo, introduzindo novas características genéticas em portfólios de produtos. Os avanços tecnológicos nas práticas de manejo da produção contribuem, igualmente para o aumento da produtividade das cultivares. Elas podem produzir mais, resistir melhor a pragas e doenças, sobreviver melhor no transporte ou simplesmente ter um sabor melhor (Glenn et al., 2017).

A obtenção de novas safras promove a diversidade agrícola e fornece uma solução para muitos dos problemas associados à agricultura intensiva. Várias ferramentas são usadas pelos melhoristas para acelerar a domesticação de plantas semi-domesticadas ou mesmo selvagens, construindo com uma base mais variada para o fornecimento sustentável de alimentos (Østerberg et al., 2017).

As ferramentas biotecnológicas também podem ser utilizadas na obtenção de plantas geneticamente modificadas (GM), que também possuem outras características sujeitas a proteção, devido aos genes inseridos nela.

Uma semente geneticamente modificada possui três componentes passíveis de proteção por patentes, o germoplasma vegetal, isto é, a própria semente; as sequências de genes ou características genéticas que resultam em uma mudança específica, e os processos como as ferramentas de pesquisa, necessárias para incorporar a nova característica genética na célula vegetal. As patentes de utilidade pública são criadas sob a lei regular de patentes. No caso de tecnologias geneticamente modificadas patenteadas, a proteção por patente concede ao seu proprietário direito exclusivo de uso da tecnologia, o que 
permite coletar royalties sempre que a tecnologia é usada. Essa proteção gerou grandes fluxos de receita para soja e canola geneticamente modificadas (Gray et al., 2017).

A proteção de variedades de plantas é essencial para o desenvolvimento de uma nação, uma vez que a regulamentação proporciona a sustentabilidade e o crescimento agrícola. Um sistema eficaz e eficiente de proteção de variedades vegetais não é uma tarefa fácil, pois envolve uma ampla gama de elementos e é uma atividade baseada no conhecimento. Neste contexto, o melhoramento de plantas tem aumentado devido ao avanço dos métodos de produção, o que leva ao desenvolvimento e avanço do setor agroflorestal, e exige um sistema jurídico eficiente para manter e regular as atividades relativas à proteção de plantas (Hurston, 2019).

O estabelecimento de padrões e princípios adequados para a aplicação de normas de proteção de direitos de propriedade intelectual sobre as cultivares é medida fundamental a qualquer país, essencialmente ao Brasil, um dos países mais ricos em biodiversidade do mundo. Além disso, o uso de patentes de tecnologias associadas a estas cultivares pode ajudar a aumentar as fontes de financiamento em pesquisa convencional, desde que sejam lançadas usando mecanismos de licenciamento apropriados (Akhundjanov et al., 2020).

$\mathrm{Na}$ maioria das culturas agrícolas propagadas via sexuada, como sementes, a pesquisa varietal é apoiada a partir da coleta de royalties ou pagamentos gerados pela indústria com a venda destes propágulos. Nas culturas agrícolas contendo inovações biotecnológicas patenteadas, também são empregadas taxas de royalties ou taxas de uso técnico para determinadas características das culturas.

Os royalties de materiais vegetais protegidos são tradicionalmente determinados como parte de um acordo entre o titular do direito (o cessionário ou licenciado) e o comprador. A taxa sobre novas variedades de sementes podem assumir várias formas, como: (a) taxa de licença fixa e antecipada, paga pelos agricultores para a utilização de novas cultivares, independentemente da quantidade de sementes adquiridas e pagas antes da produção; (b) taxa por hectare de safra ou taxa tecnológica; (c) royalties de ponto de venda, que é essencialmente um valor que os agricultores pagam por quilograma de sementes quando as compram; (d) royalties de sementes salvas, que os agricultores pagam por quilograma de sementes mantidas pelo próprio agricultor para a próxima safra, com espécies que não perdem o vigor para uso nos próximos plantios; (e) royalties de ponto final, que os agricultores pagam um valor ou parcela por produção, paga no momento da colheita ou venda; e, (f) participação nos lucros de produção; que é pago após o lucro ser determinado (Arnold, 2015).

Diferentes formas de proteção à propriedade intelectual estão disponíveis para variedades de plantas e invenções biotecnológicas, incluindo os Direitos de Melhoristas de Plantas ou Proteção de Variedades de Plantas; patentes de novos genes engenheirados, características, processos; patentes de utilidade em variedades vegetais; uso do direito contratual; mecanismos biológicos (culturas híbridas); e segredos comerciais. Os Direitos de Melhoristas de Plantas é o método padrão de proteção de cultivares na maioria dos países. A estrutura legal para a implementação destes direitos, em um país ou estado, é reconhecida em nível internacional pela União Internacional para a Proteção de Novas Variedades de Plantas (UPOV), internalizada no Brasil pelo Decreto $\mathrm{n}^{\circ}$ 3.109, de 30 de junho de 1999, que promulgou a Convenção internacional para a Proteção das Obtenções Vegetais, de 2 de dezembro de 1961, revista em Genebra, em 10 de novembro de 1972 e 23 de outubro de 1978. Além da Convenção UPOV, os países que são membros da Organização Mundial do Comércio (OMC) são obrigados, por seus membros, a aderir ao Acordo Internacional sobre Aspectos Comerciais Relacionados à Propriedade Intelectual (TRIPs) (Bergadá et al., 2016).

Diante desse cenário, foi objetivo desse trabalho realizar uma meta-análise visando acessar a produção científica sobre proteção de cultivares, identificar parâmetros e métodos existentes para definição das taxas de royalties e os mecanismos de cobrança adotados. 


\section{Metodologia}

O presente estudo classifica-se como descritivo e exploratório com abordagem quantitativa (Sakamoto \& Silveira, 2019). Incialmente, foram prospetados dados referentes à produção científica sobre royalties aplicados a obtenções vegetais. Para isto, foi realizada revisão sistemática a partir de artigos publicados no período de 10 anos, de 2009 até 2019, nas bases científicas Scopus (http://www.scopus.com) e Web of Science (http://www.webofknowledge.com). A pesquisa foi realizada em fevereiro de 2021 com os seguintes termos e operadores booleanos: "(royalty) and (plant variety or cultivars)" que foram prospectadas em título ou resumo de artigos científicos. Os metadados referentes as publicações científicas obtidas nas duas bases foram importados no formato BibTex, removidos os arquivos duplicados, combinados como um único conjunto de dados e analisados com o auxílio do software R versão 4.0.2 (R Core Team, 2020) e RStudio versão 1.1.463 (RStudio Team, 2016). Para realização de análises bibliométricas, estatística e construção de matrizes de dados para acoplamento bibliográfico, cocitação, análise de colaboração científica; e análise de palavras-chave, foi utilizado o pacote Bibliometrix do software R (Aria \& Cuccurullo, 2017) em interface com o browser Biblioshny (http:/www.bibliometrix.org). As bases Scopus e Web of Science são multidisciplinares e relevantes para análise bibliométrica para o tema de estudo. O fluxograma referente ao mapeamento científico é apresentado na Figura 1.

Figura 1. Fluxograma do processo de mapeamento científico sobre estimativas de taxas de royalties para cultivares.

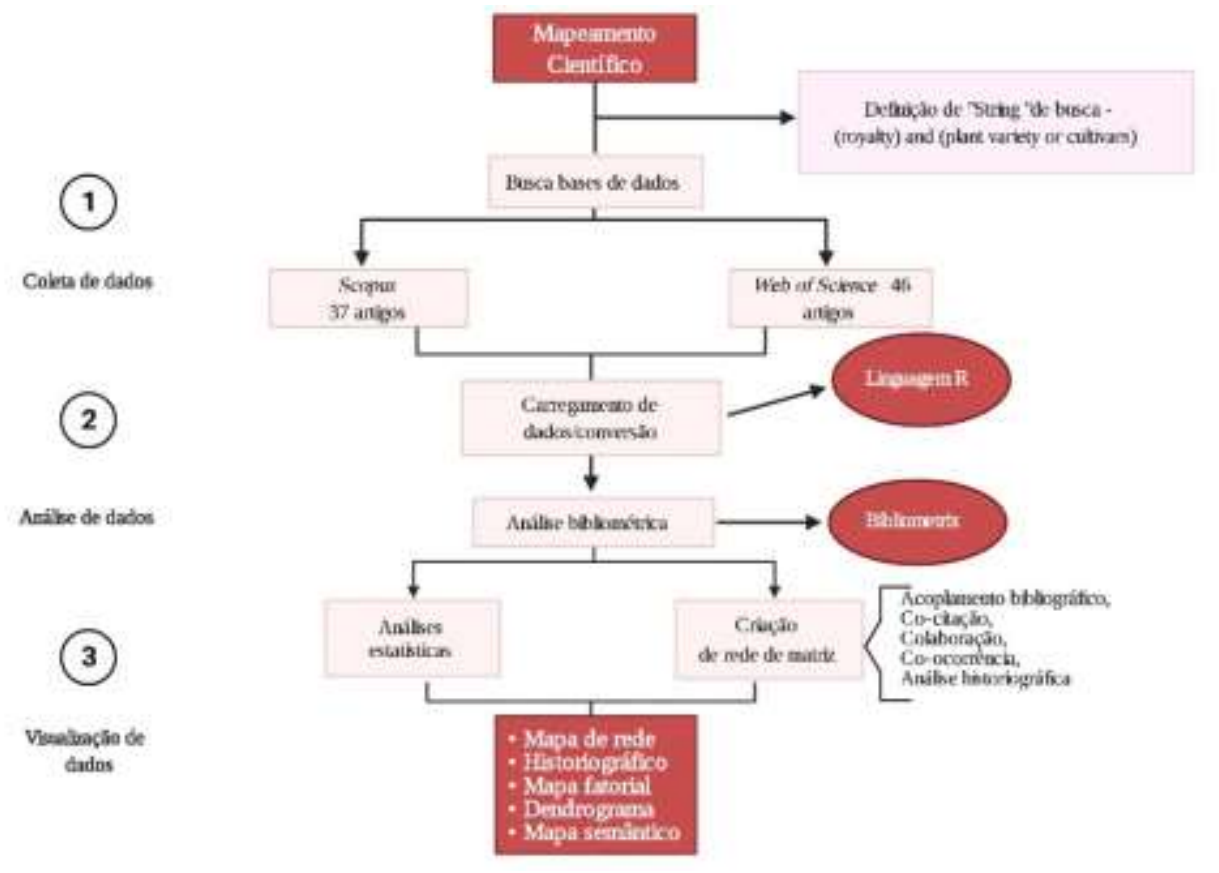

Fonte: Autores (2021).

Na Figura 1 apresenta-se 3 etapas na obtenção da bibliografia relacionada ao tema. Na etapa 1 houve a coleta de dados nas bases de artigos científicos, na etapa 2 procedeu-se a avaliação dos dados, e na terceira etapa a visualização, análise e interpretação dos resultados. Após essas etapas foi realizado um processo de refinamento, todos os arquivos foram revisados pelo título e resumo e retirados aqueles que não se enquadraram na pesquisa, e realizada a leitura completa dos artigos selecionados.

A multiplataforma de sistema de informação geográfica QGIS versão 3.4 (QGIS.org, 2021) foi utilizada para obtenção da distribuição dos países de acordo com o tipo de proteção sobre novas cultivares. 


\section{Resultados e Discussão}

Foram prospectados 83 documentos indexados nas bases Scopus (37) e Web of Science (46). Após o tratamento dos dados e remoção de documentos duplicados restaram 43 artigos científicos. Com uma publicação média de 6,7 publicações por ano. Média de 10 citações por documento (Figura 2).

Figura 2. Principais periódicos quanto ao número de artigos publicados e ao índice-H.

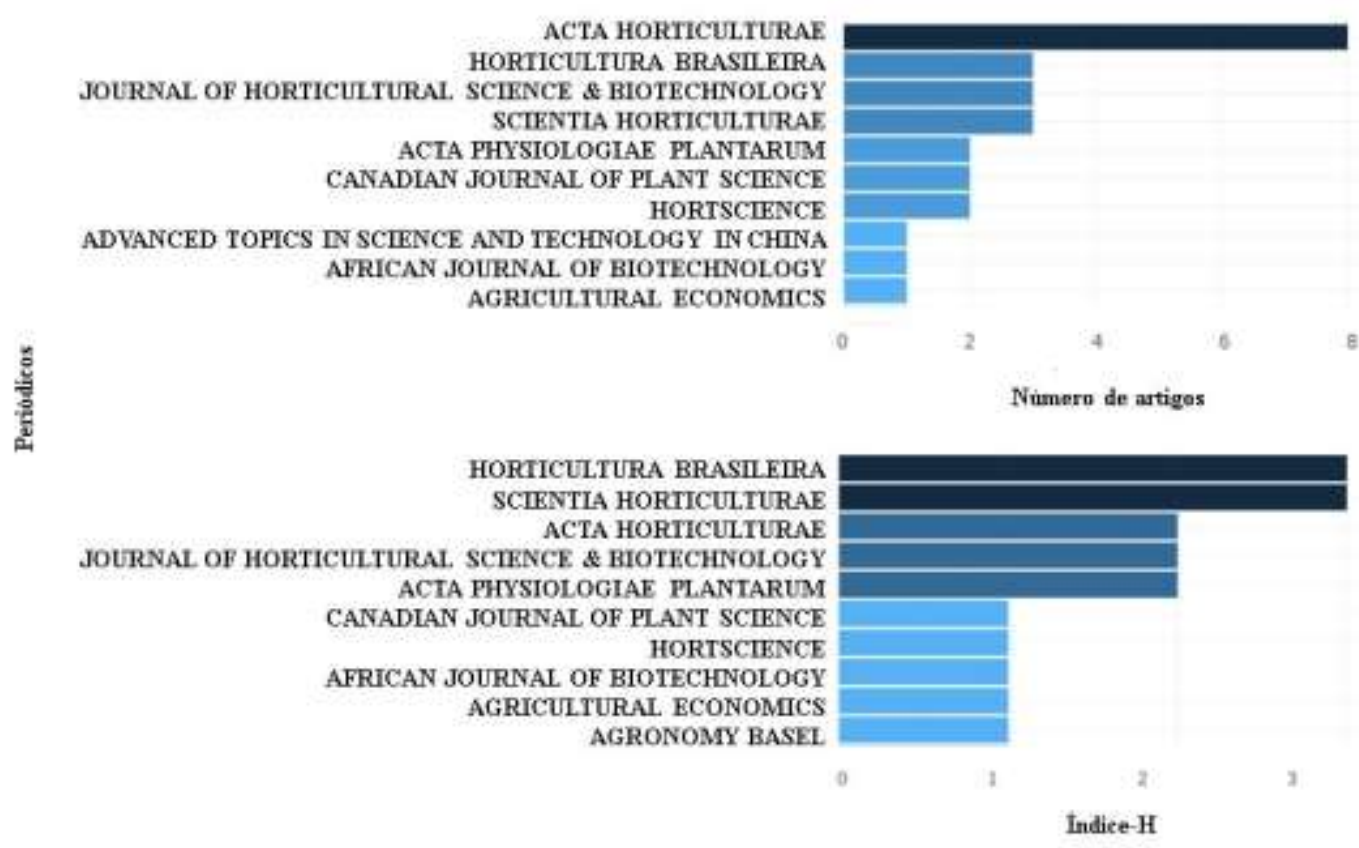

Fonte: Autores (2021).

Na Figura 2 são apresentados os periódicos e o índice-H, quanto mais intensa é a cor das barras no gráfico, maior o índice. O índice-h de um pesquisador é definido como o maior número "h" de artigos científicos desse pesquisador que têm pelo menos o mesmo número " $h$ ” de citações cada um. Para ter um índice-h elevado, é preciso publicar artigos que repercutam na comunidade científica. O índice-H foi proposto em 2005 pelo físico argentino Jorge Hirsch, professor da Universidade da Califórnia, San Diego, como uma ferramenta capaz de combinar quantidade e qualidade de produção acadêmica (Marques, 2017).

Foram observados um total 171 autores e 271 co-autores, sendo cinco documentos de autoria única e em média de 3,1 autores por artigo. Os principais periódicos foram Acta Horticulturae, Horticultura Brasileira, Journal of Horticultural Science \& Biotechnology e Scientia Horticulturae, estes destacam-se por possuírem os maiores fatores de impacto (H-index) entre os periódicos com trabalhos publicados na área (Figura 2).

Quanto ao número de citações, as revistas Plant Physiology com 83 citações, Journal Plant (60), Plant Cell (42) e Journal of Experimental Botany (34) obtiveram os maiores índices. Entre várias fontes, periódicos são uma das valiosas fontes primárias de informação. A importância da literatura de artigos em periódicos são informação; e cobrem novas ideias pesquisáveis. O conceito de periódicos centrais foi usado pela primeira vez por Bradford em 1934 e ficou conhecido por Lei de Bradford. A Lei de Bradford descreve como a literatura sobre um determinado assunto está disseminado ou distribuído nas fontes de publicação. As revistas científicas são organizadas para abranger determinado escopo, e os artigos podem ser divididos em zonas (Wardikar \& Gudadhe, 2013). Aplicada a análise estatística, baseada na Lei de Bradford, foi verificada a 
formação do grupo de periódicos centrais e respectivos ranks elencados a seguir: Acta Horticulturae (8), Horticultura Brasileira (5), Journal of Horticultural Science \& Biotechnology (5) e Scientia Horticulturae (5).

A informação científica vem através do número de publicações, o que pode ser justificado pela necessidade de avaliar parâmetros fisiológicos na caracterização e distinção de novas cultivares.

Os principais termos encontrados nas palavras-chave estão apresentados na Figura 3.

Figura 3. Evolução anual da ocorrência dos principais termos.

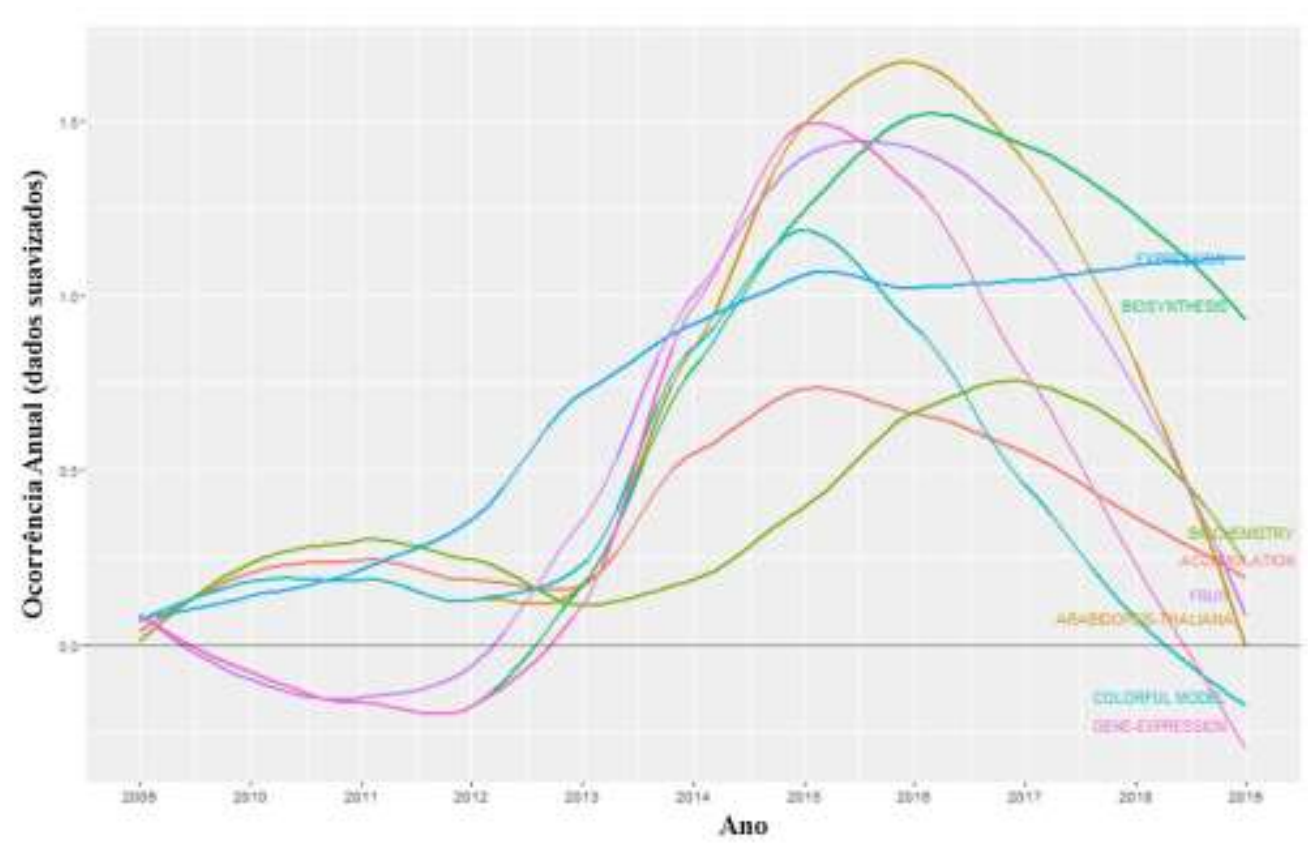

Fonte: Autores (2021).

Na Figura 3 se apresenta o espaço temporal de estudo (2009-2019) e a ocorrência dos termos encontrados nos artigos prospectados. Os termos observados na Figura 3 foram "expression" com 23\%, seguida de "Arabidopsis thaliana" e "biosynthesis" (20\%),", "fruit" com 17\%, "accumulation", "biochemistry", "colorful model", "gene-expression" e "MYB transcription factor" representando $11 \%$ cada, e "anthocyanin" com 9\%. Os termos estão conectados a características das variedades, e sempre são desafio em pesquisas científicas, uma vez que para a proteção as cultivares devem ser apresentados descritores com distinguibilidade, que sejam homogêneos para o material em questão e estáveis (DHE). A cultivar deve ser claramente distinguível (por margem mínima de descritores) de quaisquer outras cultivares na data de pedido de proteção. Para o período analisado, 2009 a 2019, o número de publicações por ano variou de 1, em 2013, e 12 em 2015 (Figura 4). 
Figura 4. Produção científica anual por autor de artigos sobre cobrança de royalties para cultivares, no período de 2009 a 2019, indexadas nas bases Scopus e Web of Science.

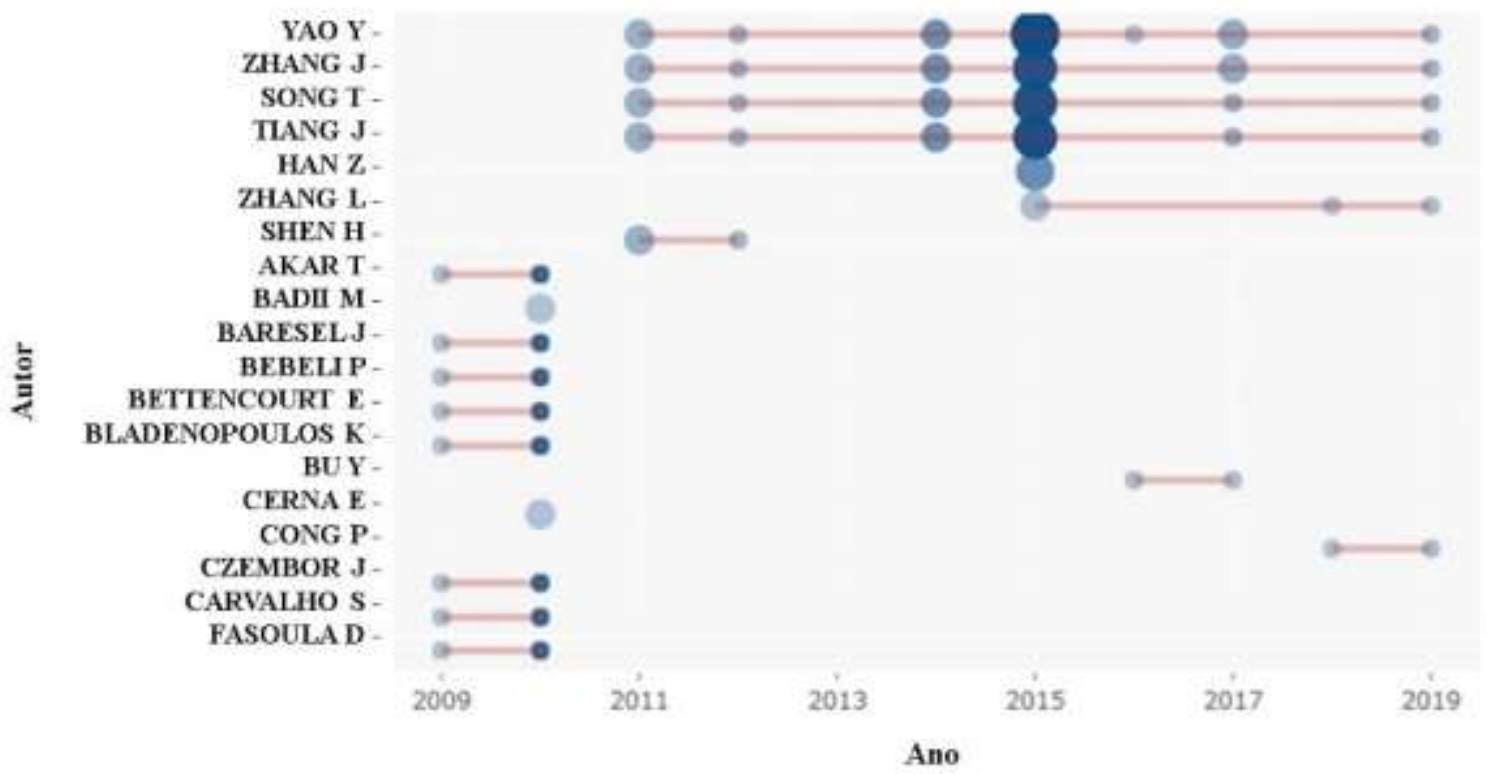

Fonte: Autores (2021).

Na Figura 4 os autores mais produtivos foram são apresentados no espaço temporal de 2009 a 2019 . O tamanho das bolhas é proporcional ao número de trabalhos publicados e, o nível de transparência é inversamente proporcional a quantidade de publicações. Observou-se Y. Yao com 18 publicações, J. Zhang com 14, T. Song e J. Tian com 13. Em 2015 houve um pico nas publicações lideradas pelos mesmos autores representados. Nesse mesmo ano, o governo canadense aprovou a lei de crescimento agrícola como forma de aumentar o investimento no melhoramento genético. A aprovação dessa lei fez com que o Canadá cumprisse a convenção da UPOV de 1991, fortalecendo significativamente o direito de propriedade intelectual (Intellectual Property Rights - IPRs) dos melhoristas de plantas (Gray et al., 2017).

A China ocupa a primeira posição entre os países com maior produção científica sobre o tema, com 20 artigos, seguida dos Estados Unidos da América (6) e Brasil (4) (Figura 5). 
Figura 5. Distribuição geográfica dos países por produção científica em pesquisa sistemática vinculada aos royalties em cultivares.

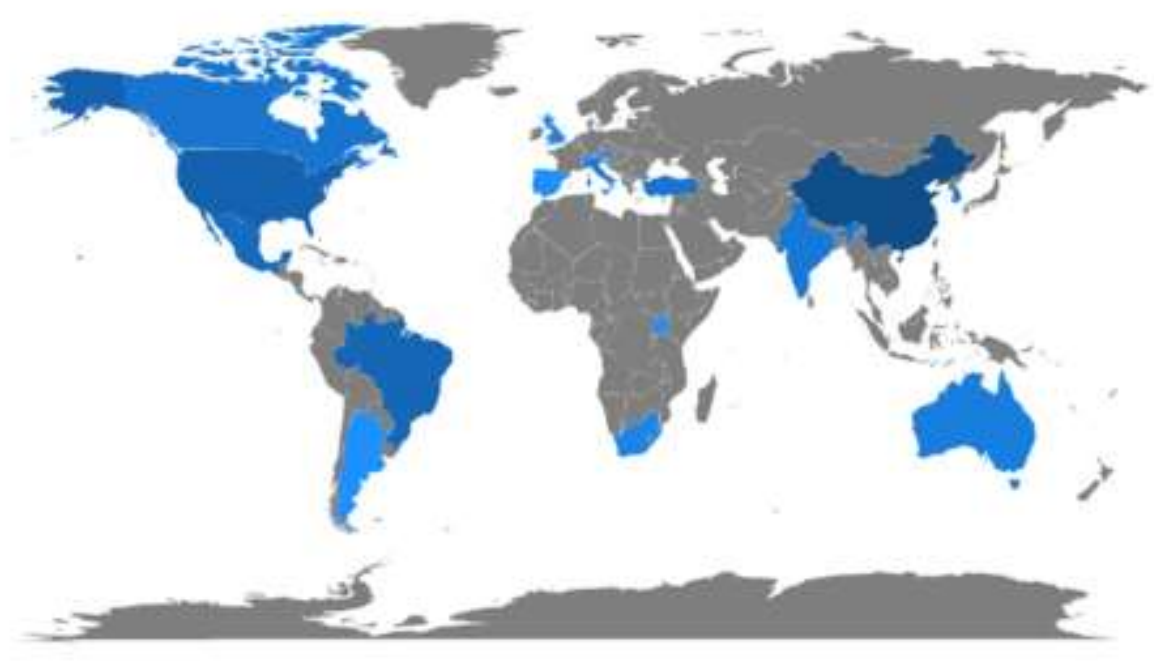

Fonte: Autores (2021).

Na Figura 5, estão identificados os países mais citados, nos quais a intensidade da cor é diretamente proporcional ao número de artigos produzidos nas diferentes regiões do mundo. Os países mais citados nos manuscritos foram China com 255 citações, Reino Unido com 155 e Brasil com 40.

Após o processo de refinamento 26 artigos foram excluídos por estarem fora do contexto. Dessa forma, obteve-se uma amostra de estudo de 17 artigos, para os quais, os resultados serão discutidos a seguir.

Dentre os periódicos mais relevantes destaca-se a Acta Horticulturae com cinco publicações e fator de impacto de 0,23. A Horticultura Brasileira é uma revista da Associação Brasileira de Horticultura, teve duas publicações e fator de impacto de 0,58. As revistas Agricultural Economics e Economic Modeling tiveram uma publicação cada e foram as revistas com maiores fatores de impacto, 2,46 e 2,36.

Com relação às áreas de pesquisa, o periódico Agricultural and Biological Sciences concentra 35,29\% das publicações; Agriculture 29,41 \% Social Sciences e Plant Sciences 17,47\%; Economics, Econometrics and Finance, Environmental Science e Business Economics representaram 11,76\% das publicações e Multidisciplinary 5,88\%.

Nos artigos, foi possível observar que Brasil, Argentina, Uruguai Paraguai, China, África do Sul e Nova Zelândia adotaram medidas para cumprimento do acordo TRIPS de 1978 (Tabela 1).

Tabela 1. Resumo da revisão sistemática com os membros da União Internacional para Proteção de Novas Obtenções Vegetais (UPOV) de acordo as atas de 1978 e 1991 e as respectivas cultivares protegidas.

\begin{tabular}{cccc}
\hline \multicolumn{2}{c}{ UPOV 1978 } & & \multicolumn{2}{c}{ UPOV 1991 } \\
\cline { 2 - 4 } Países & Cultivares & Países & Cultivares \\
\hline África do Sul & Trigo & Alemanha & Frutas e Hortaliças \\
Argentina & Soja & Austrália & Trigo \\
Brasil & Soja, pêssego & Canadá & Trigo, batata, maçã e morango \\
China & Não informado & Dinamarca & Frutas e hortaliças \\
Nova Zelândia & Frutas & Espanha & Pêssego \\
Paraguai & Soja & Estados Unidos & Trigo, mirtilo, maçã e morango \\
& & Holanda & Batata \\
& & Suíça & Frutas e hortaliças \\
\hline
\end{tabular}

Fonte: Autores (2021). 
Na Tabela 1 é apresentado o resumo dos dados obtidos na revisão bibliométrica com os membros da União Internacional para Proteção de Novas Obtenções Vegetais (UPOV) de acordo as atas de 1978 e 1991; e as respectivas cultivares protegidas.

Nos países listados (Tabela 1), o direito de proteção sobre o material propagativo incide na comercialização, oferta, venda e uso repetitivo para produção de uma cultivar. A produção de material propagativo entenda-se como a produção de sementes e outras estruturas vegetais, aptas a possibilitar o surgimento de nova planta. Dessa forma, os royalties incidem sobre a comercialização destes propágulos.

Foram identificados trabalhos com foco na Holanda, França, Espanha, Reino Unido, Alemanha, Canadá, Dinamarca, Suíça e Estados Unidos, os quais optaram pela ata de 1991 da UPOV, onde o direito de proteção sobre o material propagativo incide sobre a produção ou reprodução; armazenamento para fins de reprodução; oferta; venda ou outro tipo de comércio. A cobrança de royalties incide sobre o acondicionamento, importação e exportação do material; e da colheita.

No Paraguai as variedades de plantas são protegidas pelos direitos do melhorista de acordo com a Lei de Proteção de Sementes e Variedades (Seed and Varieties Protection Law) n. ${ }^{\circ}$ 385/1994. A Lei n. ${ }^{\circ}$ 988/1996 aprovou a participação do Paraguai na UPOV de 1978. O agricultor que guarda (salva) as sementes de uma cultura contendo a tecnologia é obrigado a declarar a quantidade de semente salvas e pagar os respectivos royalties fixados; este pagamento cobre o uso em apenas uma estação de cultivo.

Na revisão de literatura foram constatadas cobranças de royalties de ponto final na Austrália, Canadá, França, Inglaterra e África do Sul; e royalties de sementes salvas na Alemanha e Dinamarca.

No Brasil a proteção da cultivar necessita que esta seja produto de melhoramento genético, nova, distintiva, homogênea, estável, passível de proteção e de receber a denominação adequada (Cunha, 2011).

Nem todos os países foram citados na revisão bibliográfica no espaço temporal analisado, no entanto, convém citá-los de forma a comparar e identificar variações na proteção e cobrança de royalties. Como por exemplo, na Itália é possível proteger novas variedades de plantas com um sistema nacional de proteção, através do Código de Propriedade Industrial (Decreto 10 de fevereiro de 2005 n. $^{\circ}$ 30), ou com um sistema europeu baseado no Regulamento do Conselho n..$^{\circ}$ 2100/94, do qual a Itália ratificou a sua adesão em 1986 de acordo com a ata da UPOV de 1978. Para sementes de soja não existem associações ou consórcios que coletam royalties sobre sementes licenciadas ou salvas na Itália. Portanto, é praticamente normal que, o titular do direito ou a empresa de sementes, colete os royalties de seu próprio material, principalmente por meio da venda de sementes oficialmente certificadas.

O uso de sementes certificadas no México é muito alto, estimado em quase $90 \%$. Contudo, devido à natureza pública dos lançamentos de variedades, muitas dessas sementes não atraem o pagamento de royalties para o melhorista. As leis de Direito de Melhoristas de Plantas são aplicadas e os royalties são cobrados pelo Serviço Nacional de Inspeção e Certificação de Semillas (SNICS). Sementes salvas não são amplamente utilizadas no México, portanto, não desempenham um papel significativo no cálculo da arrecadação de royalties.

Na Figura 6 estão apresentados os países que usam proteção sui generis ou combinação patente/sui generis encontrados na revisão. 
Figura 6. Distribuição dos países de acordo com o tipo de proteção sobre novas cultivares.

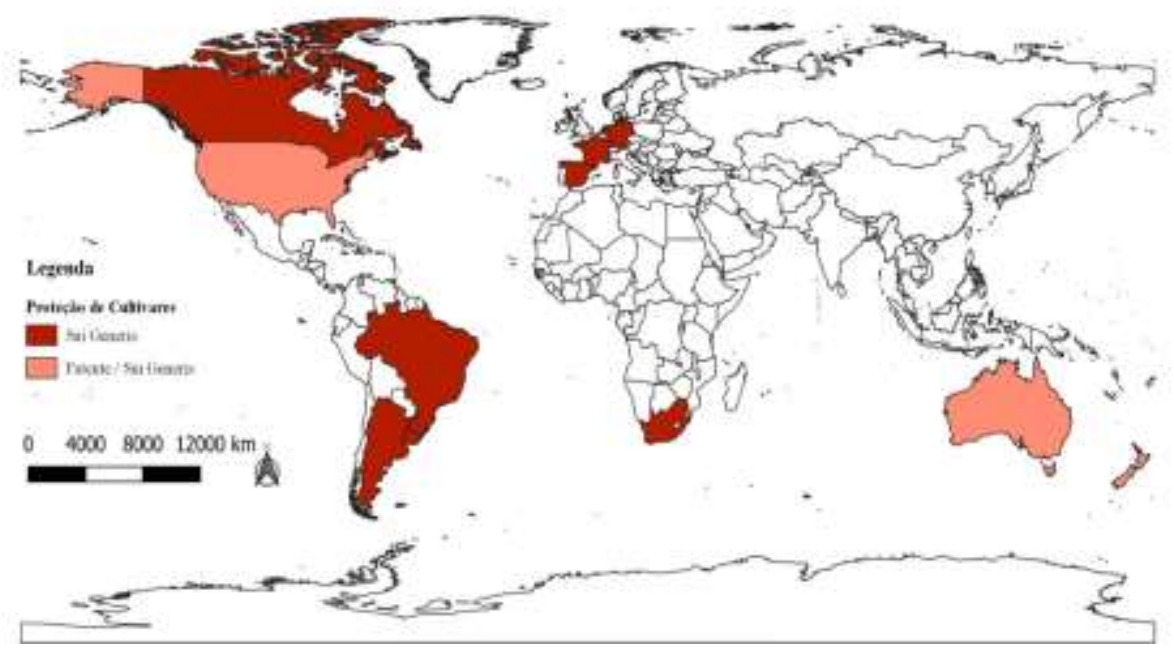

Fonte: Autores (2021).

Na Figura 6 os Estados Unidos, Austrália e Nova Zelândia aparecem como tendo optado por um sistema de proteção misto, que combina proteção por patente e sui generis sobre novas cultivares. Países como Argentina, Brasil, Uruguai, Canadá, Alemanha, França, Espanha, Holanda e África do Sul optaram pelo sistema de proteção sui generis sobre novas cultivares.

Dentre os 17 artigos filtrados, os Estados Unidos da América (EUA) com 5 artigos e Brasil com 3 artigos são os países com maior representatividade de publicações. A Espanha com 3 artigos; África do Sul e Canadá com 2 artigos; seguidos de China e Suíça com 1 artigo.

Nos EUA as cultivares podem ser patenteadas e a semente salva pelo agricultor é ilegal em variedades patenteadas. Em algumas jurisdições dos Estados Unidos, para culturas reproduzidas vegetativamente, os royalties são coletados no ponto de venda de produtos colhidos. Nesse caso, a reprodução assexuada de plantas, é por exemplo, a realizada para videiras, árvores frutíferas e plantas ornamentais, desde 1930 sob a Lei de Patentes de Plantas (Plant Patent Act). Para outras cultivares não híbridas, os inventores conseguiram obter os Direitos de Melhoristas de Plantas (Plant Breeders' Rights) para as espécies propagadas sexuadamente, na forma de sementes, por exemplo como trigo, algodão, soja e canola; desde 1970 sob a Lei de Proteção de Variedades de Plantas (Plant Variety Protection Act). O sistema de proteção dos Estados Unidos é de três maneiras: (1) a patente de utilidade pública (desde 1985); (2) a Lei de Proteção de Plantas (desde 1930); e, (3) a Lei de Variedades Vegetais (desde 1970). Cada uma das leis citadas protege um tema específico; e possui diferentes requisitos de proteção. A patente de utilidade inclui plantas geneticamente modificadas e componentes de plantas (por exemplo, genes e células). A Lei de Patentes de Plantas protege plantas reproduzidas assexuadamente. A Lei de Proteção de Variedades de Plantas protege plantas reproduzidas sexuadamente, proteção do tipo UPOV (Correa, 2015).

No Brasil antes da LPC, todas as cultivares lançadas eram de domínio público e não houve qualquer tipo de proteção de planta, royalties ou similar, até 1997. Após a LPC o processo de registro de novas cultivares, coube ao Ministério da Agricultura, Pecuária e Abastecimento (MAPA) sendo uma etapa importante para a produção e comercialização de sementes. O registro garante a identidade genética e qualidade varietal para programas de melhoramento, e é exigência para o comércio. A proteção é facultativa e garante royalties para empresas de melhoramento vegetal, sejam elas privadas ou públicas (Bruch, 2006).

Nos artigos prospectados, verificou-se que os autores internacionais são mais citados (24) em comparação com autores brasileiros, que tem um quantitativo global de 10 citações. A partir desta pesquisa, observou-se diferentes formas de cobrança de royalties de cultivares protegidas. O desenvolvimento de cultivares pelo setor público nos EUA aborda a 
redistribuição de fundos de royalties para reforçar os fluxos de receita e simplificar o processo de troca de germoplasma, para aumentar orçamentos de cultivares bem-sucedidas (Shelton \& Tracy, 2017).

Os direitos de propriedade intelectual relacionados à soja geneticamente modificada, tolerante ao glifosato no Brasil, foram analisadas em relação às diferentes modalidades de proteção das criações intelectuais no campo da biotecnologia agrícola, de acordo com a legislação brasileira relacionada ao tema (Lei de Propriedade Industrial - n. ${ }^{\circ}$ 9. 279/96 e Lei de Proteção de Cultivares - n. ${ }^{\circ}$ 9. 456/97, Lei de Sementes e Mudas $n^{\circ} 10.711 / 03$ ), e com base nos tratados internacionais firmados pelo Brasil e cobrança de royalties por terceiros pelo uso da tecnologia empregada (Arias et al., 2017). Na legislação de sementes, os Direitos dos Melhoristas de Plantas têm sido abordados com o Acordo Geral de Tarifas e Comércio (GATT) e outros acordos internacionais ampliaram os poderes dos obtentores e melhoristas (Clunies-Ross, 1996). A partir de então, os obtentores de plantas têm o direito e controle quase total sobre o material reprodutivo gerado a partir de variedades de plantas que eles desenvolveram. Eles não só podem cobrar royalties sobre suas sementes, mas também podem licenciar a quem pode multiplicá-las; e cultivá-las para quem as safras devem ser vendidas.

Alguns países, como Canadá e França, não permitem que os inovadores patenteiem suas variedades de plantas. No entanto, os Direitos dos Melhoristas de Plantas (Plant Breeders' Rights-PBR) é reconhecido por um sistema sui generis. Outros países, por exemplo, os Estados Unidos, o Japão, a Austrália permitem que os sistemas de patente e os Plant Breeders's Rights coexistam (Hervouet \& Langinier, 2018).

O sistema de proteção de variedades de plantas da União Europeia (UE) baseia-se nos princípios da ata da UPOV de 1991, através do regulamento da UE 2100/94 sobre o Direito Comunitário de Variedades Vegetais (The Community Plant Variety Rights). Esses direitos incorporam o princípio da isenção dos obtentores, livre acesso a variedades protegidas para o desenvolvimento e exploração de novas variedades de plantas em pesquisas (Jong, 2020).

O Reino Unido manteve as formas atuais de Lei de Direito dos Melhoristas de Plantas (Plant Breeders' Rights), baseadas nos princípios da UPOV. Em 1964, o Reino Unido aprovou a Lei de Variedades Vegetais e Sementes do Reino Unido para se ajustar aos princípios da UPOV, e desde então adaptou seu sistema às mudanças de acordos UPOV e legislação da União Europeia. Em 1994, aprovou legislação para tornar-se compatível com o UPOV Ata 91, permitindo que os melhoristas cobrassem royalties sobre sementes salvas (Farm Saved Seeds - FSS), desde que seja inferior aos royalties sobre sementes certificadas.

As leis da Europa e do Reino Unido obrigam os agricultores a declarar o uso de sementes agrícolas, e conta com a honestidade daqueles que declaram o uso de cultivares protegidas às Sociedades Britânicas de Melhoristas de Plantas (British Society of Plant Breeders). A legislação prevê três maneiras diferentes para os royalties de sementes salvas. A Sociedade Britânica e a União Nacional de Agricultores (National Farmers Union-NFU) negociaram um acordo contratual e estabeleceram uma taxa uniforme de royalties para sementes salvas, que atualmente é de 52,5\% da taxa média ponderada de royalties sobre sementes certificadas cultivadas no ano anterior (Gray et al., 2017).

$\mathrm{Na}$ França existem royalties sobre sementes compradas e salvas, bem como royalties de sementes coletados via ponto final. A maioria das cultivares de grãos é protegida por um sistema de gerenciamento de licenciamento chamado SICASOV (Societé Coopérative S'intérêt Collectif Agricolr des Sélectionneurs Obtenturs de Variétés Vegétales), que recolhe royalties. Os royalties são coletados em duas etapas, uma junto aos agricultores de sementes comerciais adquiridas ou de sementes salvas, em toneladas; e outra com as vendas que estão sujeitas a definição de valor pago no primeiro ponto de venda (Arnold, 2015).

A Argentina é membro da UPOV desde 1994 (Lei de 1978) e da OMC desde 1995. A lei n. 20247/73 sobre Sementes e Criações Fitogenéticas aprovada em 1973, conhecida como a Lei de Sementes, fornece a estrutura legal para os direitos dos melhoristas de plantas. No período de criação da lei o modelo de agricultura era muito diferente do atual, por isso, várias 
discussões ocorreram para revisar a lei (Bergadá et al., 2016).

Os melhoristas/obtentores de variedades de plantas na Argentina desenvolveram estratégias para superar todos os tipos de abuso da propriedade intelectual protegida. A indústria formou associações privadas sem fins lucrativos, com o objetivo de implementar sistemas para proteger os direitos dos melhoristas e produzir um retorno sobre o investimento no melhoramento de plantas na Argentina. A Asociación Argentina de Protección de las Obtenciones Vegetales (ArPOV) coordena e facilita a administração e implementação do Sistema de royalties estendido (Extended Royalty System - ERS) para variedades de plantas na Argentina. Os agricultores podem usar sementes salvas sem limitação para materiais não transgênicos. Contudo, para obter o pagamento de royalties sobre sementes salvas, melhoristas/obtentores usam o sistema ERS (Le Buanec \& Ricroch, 2014).

A China é membro da UPOV desde 1999 (Lei de 1978) e da OMC desde 2001. É difícil ter uma visão clara da situação devido à falta de ampla transparência de leis e da deficiência dos direitos da propriedade intelectual. Os agricultores podem usar sementes salvas para cultivares não transgênicas sem o pagamento de royalties. No entanto, alguns governos provinciais fornecem subsídios para incentivar os agricultores a comprar sementes de qualidade comercial para grandes culturas, como cereais (Le Buanec \& Ricroch, 2014).

Em 1994, o Uruguai foi o primeiro país da América do Sul a ratificar a UPOV; portanto, atualmente sua lei de sementes se baseia na Lei UPOV de 1978, com importantes emendas e melhorias de acordo com a ata de 1991. A Associação Uruguaia de Criadores de Plantas (URUPOV) foi fundada no mesmo ano e é uma associação privada focada na coleta e aplicação de royalties. Em 1997, o Instituto Nacional de Sementes (INASE) foi criado e é o órgão oficial responsável pelos direitos de melhoristas de plantas. O Uruguai usa um sistema de valor tecnológico ou sistema de royalties estendido que está em vigor desde 2003. Seu principal objetivo é coletar royalties de sementes salvas. Atualmente, isso está sendo aplicado para soja, trigo, cevada e ervilhas. Quando a semente é comprada, é assinado um contrato entre o obtentor e o produtor, no qual são estabelecidas as condições para produzir e usar as sementes salvas (Curtis \& Nilsson, 2015).

O marco regulatório brasileiro referente à propriedade intelectual passou por transformações significativas a partir da segunda metade da década de 1990, logo após a assinatura, na Organização Mundial do Comércio (OMC), do Acordo sobre Aspectos dos Direitos de Propriedade Intelectual - Trade Related Aspects of Intellectual Property Rights (TRIPS). Como o desenvolvimento de uma nova semente decorre em média de dez ou mais anos em um laboratório de pesquisa agropecuária, é relevante que a economia esteja preparada para regular a questão dos direitos de propriedade, que possam remunerar o investimento realizado neste período de pesquisa. As resoluções aprovadas neste acordo entraram em vigor somente em 1996, com prazo de onze anos para serem totalmente implantadas. Pela Lei no 9.279/1996, Lei de Propriedade Industrial (Brasil, 1996), regularam os direitos e as obrigações relativas à propriedade industrial no Brasil. Posteriormente, conforme a Lei $n^{\circ}$ 9.456/1997 (Brasil, 1997), foi promulgada a Lei de Proteção de Cultivares (LPC), que introduziu uma política de proteção intelectual específica para a agricultura.

Desde a promulgação da LPC, os mecanismos de proteção à propriedade intelectual tornaram-se importantes para a coordenação e gestão da pesquisa agropecuária e para o fortalecimento do aspecto institucional da pesquisa pública.

No Brasil, a Lei que regula direitos e obrigações relativos à propriedade industrial é a Lei no 9.279/ 96 (Brasil 1996) e para obtenções vegetais, a Lei de Proteção de Cultivares - Lei PVP 9.456/97. Na segunda metade da década de 90, que o Brasil começou a projetar uma estrutura reguladora para a concessão de direitos de propriedade às plantas e a regulação de organismos geneticamente modificados (OGM). Para os OGM a primeira lei foi aprovada em 1995 (Lei no 8.974/95), revogada pela Lei $n^{\circ} 11.105$, de 2005, e decreto $n^{\circ} 5.591$, de 22 de novembro de 2005. A liberação de plantas geneticamente modificadas é apreciada pela Comissão Técnica Nacional de Biossegurança (CTNBio), encarregada de julgar os processos relacionados às atividades envolvendo organismos geneticamente modificados (OGM) (Figura 7). 
Figura 7. A proteção da Propriedade Intelectual em variedades de plantas, contendo genes inseridos.

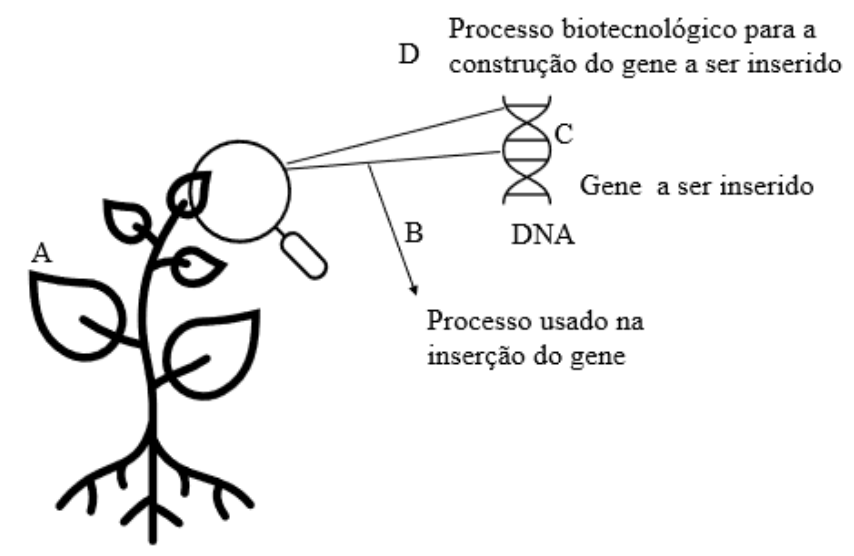

Planta Geneticamente Modificada

A - planta geneticamente modificada - cultivar protegida, proteção sui generis (Brasil - Lei 9.456/1997); B - processos usados na inserção de um novo gene (patente de processo - Brasil - Lei $\mathrm{n}^{\circ}$. 9.279/96); $\mathrm{C}$ - genes biotecnologicamente tratados inseridos na planta (patente de produto - Brasil - Lei $\mathrm{n}^{\circ}$. 9.279/ 96); $\mathrm{D}$ - processos usados para a construção do gene a ser inserido (patente de processo - Brasil - Lei no. 9.279/ 96).

Fonte: Autores (2021).

Na Figura 7 se apresenta a proteção da Propriedade Intelectual em variedades de plantas, contendo genes inseridos. As sequências gênicas e proteínas de plantas e seus processos de fabricação ou manipulação são passíveis de patenteabilidade, ao passo que as respectivas plantas inteiras podem ser objeto de certificados de proteção de cultivar. Assim, as inovações referentes ao gene engenheirado e os processos são patenteados. Os direitos de propriedade sobre inovações genéticas em sementes de soja, como a inserção de genes engenheirados, estão sujeitos a fácil apropriação porque as características biológicas da semente, ou seja, a auto reprodutibilidade (devido a autofecundação predominante na espécie) e como facilmente coloca essas inovações em acesso público. Como resultado, as empresas realizam esforços de proteção por meio do desenvolvimento de arranjos organizacionais, a fim de obter os royalties sobre a tecnologia (Monteiro \& Zylbersztajn, 2013).

No sistema brasileiro de coleta de royalties de sementes, os obtentores de plantas permitem a multiplicação das sementes aos produtores (material para propagação) para atender a demanda por volumes para uso comercial em plantios. Depois, as vendem como material propagativo aos produtores de grãos (material para uso industrial/alimentação). Muitas vezes, a mesma instituição é obtentora e produtora de sementes. As produtoras de sementes vendem sementes para os agricultores, que, exceto nos casos isentos prescritos na LPC, não podem legalmente salvar sementes sem pagar royalties aos obtentores (Flister \& Galushko, 2016).

Em muitas partes do mundo, os melhoristas/obtentores usam os ganhos em produção agrícola como parâmetro para determinar o valor de royalties a serem obtidos pelo uso da cultivar protegida. Na maioria das vezes, isso envolve a coleta de royalties de produtores de sementes que têm licença para produzir e vender os propágulos como sementes certificadas. $\mathrm{Na}$ Austrália e na África do Sul o pagamento de royalties de variedades protegidas, no ponto de venda dos produtos, é mais comum para cereais. Um sistema semelhante é empregado para certas espécies de flores que são cultivadas na África Oriental e comercializadas na Holanda, onde os royalties são determinados e coletados no ponto de venda, o que normalmente ocorre no leilão de flores (De Jonge \& Munyi, 2016).

A partir da revisão sistemática foi possível analisar a produção científica da proteção das principais variedades no Brasil e no mundo, como são cobradas as taxas de royalties e os mecanismos de cobrança. Cabe ressaltar que os periódicos analisados não forneceram informações de como são taxados, em detalhes, os royalties, apenas relataram o tipo de proteção e as cultivares estudadas. Não foi constatado nenhuma expressão matemática padrão de taxa de royalties, pois cada cultivar tem diferenças agronômicas e tecnológicas. 


\section{Conclusão}

A discussão da cobrança de royalties deve ser sempre tratada não só em nível econômico, mas também em nível socioeconômico e agrário; e existe carência na literatura científica deste tema, nos últimos 10 anos.

O mecanismo de royalties de ponto final e royalties de sementes salvas foram encontrados em grande parte dos periódicos, mas em menor número para casos e exemplos brasileiros. As respectivas taxas de royalties são cobradas mediante contratos entre agricultores, associações e empresas de melhoramento genético de acordo com a legislação de cada país.

Desta forma, diante da falta de detalhamentos nestas cobranças de royalties, abre-se lacunas para novas pesquisas com o tema visando acompanhar melhor os ganhos produtivos, e como taxá-los visando o retorno de investimentos na obtenção de novas variedades de plantas. Muitas empresas usam taxas que não são explicitamente apresentadas, portanto, é pertinente se aprofundar as discussões em royalties para cultivares de forma a publicizar quais variáveis podem ser ponderadas nesta taxação. É importante ressaltar, que existe uma tendência de valorização de processos e procedimentos mais transparentes.

A transparência nas taxações, associadas as inovações tecnológicas a serem comercializadas, são um dos pressupostos da bioeconomia. De acordo com a Confederação Nacional da Indústria, relatório 2013-2022, “A bioeconomia surge como resultado de uma revolução de inovações na área das ciências biológicas. Está relacionada à invenção, desenvolvimento e uso de produtos e processos biológicos nas áreas da biotecnologia industrial, da saúde humana e da produtividade agrícola e pecuária”. Assim, com o envolvimento de grandes empresas nacionais e multinacionais na obtenção de novas cultivares protegidas, é importante integrar a elas este conceito de bioeconomia, que só pode ser atingido, considerando mais transparência nas variáveis a serem ponderadas na taxação em royalties de inovações tecnológicas, como as cultivares.

Em futuros trabalhos é importante investigar formas de taxação de royalties, buscando a transparência. Ainda existe falta de informações das dificuldades encontradas nas cobranças de royalties, e nos grandes impactos associados a exploração de materiais protegidos de forma ilegal, com a biopirataria.

\section{Agradecimentos}

O presente trabalho foi realizado com apoio da Coordenação de Aperfeiçoamento de Pessoal de Nível Superior Brasil (CAPES) - Código de Financiamento 001.

\section{Referências}

Akhundjanov, S. B., Gallardo, R. K., McCluskey, J. J., \& Rickard, B. J. (2020). Commercialization of a demand-enhancing innovation: The release of a new apple variety by a public university. Economic Modelling, 86(June 2019), 88-100. https://doi.org/10.1016/j.econmod.2019.06.004

Aria, M., \& Cuccurullo, C. (2017). Bibliometrix: An R-tool for Comprehensive Science Mapping Analysis. Journal of Informetrics, 11(4), 959-975. https://doi.org/10.1016/j.joi.2017.08.007

Arias, A. C. R., Palacio, J. L., Chaparro-Giraldo, A., \& López-Pazos, S. A. (2017). Patents and genetically modified soybean for glyphosate resistance. World Patent Information, 48, 47-51. https://doi.org/10.1016/j.wpi.2017.01.002

Arnold, A. J. (2015). A Game-Theoretic Approach to Modelling Crop Royalties [University of Adelaide]. https://digital.library.adelaide.edu.au/dspace/handle/2440/95230

Bergadá, P., Rapela, M., Enríquez, R., Risso, D., \& Mendizabal, J. (2016). Generating value in the soybean chain through royalty collection: an international study. BioSci Law Rev, 15(5), 169-210.

Boff, S. O. (2019). Proteção jurídica das cultivares na UPOV, no TRIPs e os limites na legislação brasileira: o embate entre interesse público e privado Legal Protection of Cultivars In UPOV, TRIPs between Public and Private Interest. XIX, 433-456.

BRASIL, Ministério da Indústria, Comércio Exterior e Serviços Instituto Nacional da Propriedade Industrial. Resolução No 169 , de 15 de Julho de 2016 (2016).

Bruch, K. L. (2006). Limites do Direito de Propriedade Industrial de Plantas. Universidade Federal do Rio Grande do Sul.

Clunies-Ross, T. (1996). Creeping enclosure. Seed legislation, plant breeders' rights and Scottish potatoes. Ecologist. 
Correa, C. M. (2015). Plant Variety Protection in Developing Countries: A Tool for Designing a Sui Generis Plant Variety Protection Sistem: An Alternative to UPOV 1991. http://www.apbrebes.org/

Cunha, E. A. B. B. da. (2011). O direito sobre novas variedades. In Proteção de cultivares no Brasil.

Curtis, F., \& Nilsson, M. (2015). Collection systems for royalties in wheat, an International study. Bio-Science Law Review, 12(6), 215.

De Jonge, B., \& Munyi, P. (2016). A Differentiated Approach to Plant Variety Protection in Africa. Journal of World Intellectual Property, 19(1-2), 28-52. https://doi.org/10.1111/jwip.12053

FAO. (2021). Conservation of agrobiodiversity of local cultivars: millet, maize, sorghum through improved participatory for food and agriculture in Senegal. Food and Agriculture Organization of the United Nations. http://www.fao.org/plant-treaty/areas-of-work/benefit-sharing-fund/projects-funded/bsfdetails/en/c/359511/?iso3=SEN

Flister, L., \& Galushko, V. (2016). The impact of wheat market liberalization on the seed industry's innovative capacity: an assessment of Brazil's experience. Agricultural and Food Economics, 4(1). https://doi.org/10.1186/s40100-016-0055-8

Giovanoli, S. M. (2014). Farm Saved Seed (FSS) and Royalty Generation for Wheat in France, United Kingdom, and Australia-Policy Implications for Canada. University of Saskatchewan.

Glenn, K. C., Alsop, B., Bell, E., Goley, M., Jenkinson, J., Liu, B., Martin, C., Parrott, W., Souder, C., Sparks, O., Urquhart, W., Ward, J. M., \& Vicini, J. L. (2017). Bringing new plant varieties to market: Plant breeding and selection practices advance beneficial characteristics while minimizing unintended changes. In Crop Science (Vol. 57, Issue 6, pp. 2906-2921). Crop Science Society of America. https://doi.org/10.2135/cropsci2017.03.0199

Gray, R. S., Kingwell, R. S., Galushko, V., \& Bolek, K. (2017). Intellectual Property Rights and Canadian Wheat Breeding for the 21st Century. Canadian Journal of Agricultural Economics, 65(4), 667-691. https://doi.org/10.1111/cjag.12142

Hervouet, A., \& Langinier, C. (2018). Plant breeders' rights, patents, and incentives to innovate. Journal of Agricultural and Resource Economics, 43(1), 118150. https://doi.org/10.22004/ag.econ.267613

Hurston, Z. N. (2019). International Overview on the Protection of Plant Varieties. Court Uncourt, 6 . https://heinonline.org/HOL/Page?handle=hein.journals/counco6\&id=40\&div=\&collection=

Jong, P. De. (2020). Wine Law and Policy. Wine Law and Policy, 34(July 1998), 7-8. https://doi.org/10.1163/9789004438316

Le Buanec, B., \& Ricroch, A. (2014). Intellectual property protection of plant innovation. In Plant Biotechnology: Experience and Future Prospects (Vol. 9783319068923, pp. 59-73). Springer International Publishing. https://doi.org/10.1007/978-3-319-06892-3_6

Marques, F. (2017). Os limites do índice-h. Boletim Técnico do PPEC, 2(1), 35-39.

Monteiro, G. F. de A., \& Zylbersztajn, D. (2013). Economic governance of property rights: Comparative analysis on the collection of royalties in genetically modified soybean seeds. Revista de Economia e Sociologia Rural, 51(1), 25-44. https://doi.org/10.1590/S0103-20032013000100002

Østerberg, J. T., Xiang, W., Olsen, L. I., Edenbrandt, A. K., Vedel, S. E., Christiansen, A., Landes, X., Andersen, M. M., Pagh, P., Sandøe, P., Nielsen, J., Christensen, S. B., Thorsen, B. J., Kappel, K., Gamborg, C., \& Palmgren, M. (2017). Accelerating the Domestication of New Crops: Feasibility and Approaches. In Trends in Plant Science (Vol. 22, Issue 5, pp. 373-384). Elsevier Ltd. https://doi.org/10.1016/j.tplants.2017.01.004

QGIS.org. (2021). QGIS Geographic Information System (3.4). QGIS Association. https://docs.qgis.org/3.16/en/docs/developers_guide/index.html

R Core Team. (2020). R: A Language and environment for statistical computing. Vienna: R Foundation on Statistical Computing (1.3.1073).

RStudio Team. (2016). RStudio: Integrated Development for R. MA: RStudio. http://www.rstudio.com/

Sakamoto, Cleusa Kazue \& Silveira, Isabel Orestes. (2019). Como fazer projetos de Iniciação Científica. Pia Sociedade de São Paulo-Editora Paulus.

Shelton, A. C., \& Tracy, W. F. (2017). Cultivar development in the U.S. public sector. Crop Science, 57(4), 1823-1835. https://doi.org/10.2135/cropsci2016.11.0961

Wardikar, V. G., \& Gudadhe, V. P. (2013). Application of Bradford's law of scattering to the literature of library \& information science: A study of doctoral theses citations submitted to the universities of Maharashtra, India. Library Philosophy and Practice, 2013. 